\title{
Research on the Teaching Mode of Physical Education in Colleges and
}

\section{Universities}

\author{
Qiang Luo
}

Xi'an International University, Shaanxi, Xi'an, China, 710077

\section{Keywords: College Sports; Teaching Model; Research Strategy}

\begin{abstract}
In the main course of the university, the role and status of physical education cannot be ignored. We all know that college physical education has become an important part of cultivating modern talents, but nowadays, under the background of development, there are still many deficiencies in the teaching mode of physical education in colleges and universities, which is of great significance to improve and improve the quality of physical education in colleges and universities brought a lot of trouble and obstacles. In the face of such a situation to clarify the situation at the same time to further put forward the corresponding optimization strategies and methods.
\end{abstract}

\section{Introduction}

With the reform and development of higher education in China in recent years, as one of the important components of higher education system, colleges and universities should be advancing with the times and constantly innovating and optimizing in the teaching mode so that Better to adapt to the development of the times and the pace of history. The innovation and optimization of PE teaching mode in colleges and universities is a more complicated task. How to construct a new set of new PE teaching models in line with the needs of modern higher education development should first recognize the current situation and the shortcomings can do a practical way to grasp every specific subtle links, from the basis of solving every problem, and only in this way can promote the development of college physical education and progress.

\section{The Necessity of Establishing New PE Teaching Mode in Colleges and Universities}

The establishment of a new model of physical education is a reflection of the realization of quality education in colleges and universities, which is based on years of reform and practice, and in full understanding of the basis of physical education and reform, but also reflects the development of the times education reform needs, but also reflects the basic role of physical education. In general, the quality of education is based on the teaching model as a certain educational thinking as a guide, in a certain period of time to complete the teaching content and teaching objectives, and then related to the teaching process, teaching the form of teaching system and teaching methods And so on.

After years of practice, in recent years, Chinese education quality in the direction of reform is correct, but in physical education, because of its teaching complexity and its own characteristics, resulting in difficult to integrate into the quality of education itself, so there is no the formation of a stable and systematic teaching model. Through the study of the current situation of physical education in colleges and universities, it is found that there are many unresolved phenomena in the physical education of colleges and universities, and how to establish new teaching mode is also a 
major problem in the reform of college physical education.

Teaching model is a demonstration, it can make the specific teaching theory and scientific practice teaching to achieve a combination, to a certain extent played an important role, in other words the teaching model is connected to teaching practice and teaching theory of the bridge.

\section{The Current Situation of College Physical Education}

Chinese college physical education teaching theory from the last century since the 50's there is no deviation from the framework of physical education. In general, the concept of physical education in the development and change of curriculum, teaching materials, teaching methods and teaching organization forms is not obvious, and there are still many shortcomings.

College Physical Education Objectives Are Not Clear. The demand for talented people in contemporary society is getting higher and higher, so that the cultivation of talents not only has a wide range of scientific and cultural knowledge, but also has the courage to fight and the spirit of innovation. How can modern talents better adapt to the development environment of contemporary society? First of all, we must have good psychological quality and strong physical quality as the basis and guarantee of social survival. Faced with this situation, the goal of physical education in colleges and universities must be to train lifelong sports quality as the main teaching task. However, at present, the training goal of physical education in our country is still in the level of sports technology and skills, which makes the college students' awareness of the lifelong cultivation of sports do not have enough awareness and attention, which has led many college students to leave the university after graduating from college.

The Old Teaching Model Cannot Arouse Students' Subjective Initiative Development. The teaching model is the concrete practice of the teaching system and the teaching process. It is also the bridge and the link between the teaching theory and the teaching practice. Most of the physical education modes in Chinese universities are based on the educational system established by the former Soviet educator Kloff's learning model [1]. This model is based on the teacher as the center, and let the students are always in a passive state of study, through the teacher's description and speech, and then through the qualitative teaching content in the form of irrigation to the students, this teaching mode of teaching focus is "basic Knowledge, basic skills, basic methods "of these three basic learning and mastery. This model emphasizes the foundation rather than the choice, with a heavy sense of command and no creativity and this will ignore the student's subjectivity, and thus limit the student's initiative and innovative thinking ability.

The Content of the Course Content System is Single. From the current situation of college physical education in China, divided into basic courses, options courses, elective courses and health courses. These four components take into account the physical development of college students, as well as the actual needs of college students on sports. However, in the implementation of specific courses, but ignored the sports humanities and physical exercise related to the transmission of human science knowledge. Because of the excessive emphasis on the basic knowledge and skills of sports programs, students want to learn too much knowledge content and it is difficult to meet the actual needs, leaving the lack of timeliness and long-term physical education.

In the process of teaching, the subjectivity of students is mainly reflected in two aspects: first, the actual needs of students in teaching to occupy the dominant position; second, students in the teaching of the initiative and independence embodied. Although we emphasize that quality education should take the examination as the ideal mode of education, teaching should be students as the main body, but this idea is not really reflected in the physical education. So now some of the institutions of higher learning in sports theory teaching, the actual teaching of sports, the students 
should be the main idea of the education or lack of a lack of understanding. From the point of view of sports theory teaching, the construction of sports teaching material is still based on traditional sports thought and cognition, and has always followed the traditional theoretical system and teaching material structure model. This model from the idea to the concept, from theory to practice, from the structural approach to the content form is very stiff and aging, has long been unable to meet the needs of today's society for high-quality sports talent, but also limit the students' subjective initiative And the development of innovative capacity.

At present, the university's physical education is generally regarded as a measure of students to achieve the "national sports standards" (hereinafter referred to as "standard") the only standard of physical fitness, to achieve this standard is qualified physical quality cannot be achieved is unqualified body quality [2]. There are some colleges and universities in some colleges and universities are still "standard" as the starting point of physical education and work focus, everything to "standard" on the provisions of the first, this will often lead to deviations from the objectives of college physical education. This evaluation method not only cannot give students a positive impact on the role, but will make their learning interest in sports greatly reduced, so you need to study their own new scientific teaching evaluation, so as to the development of students' sports quality promote the role.

\section{The Strategy Optimization and Methods of Constructing Efficient Physical Education Mode}

Improve the Classroom Teaching Structure. In the traditional physical education, teaching classroom structure is mostly fixed and single, and in order to make the quality of education can be effectively improved, you need to break the original fixed classroom teaching mode. In order to improve students 'interest and learning methods, teachers should adjust students' thinking and set up teaching patterns by satisfying students 'desire for sports, which can trigger students' learning motivation. In addition, the teacher should also be based on student activities to arrange teaching materials counseling, according to a certain amount of teaching materials counseling order, so that teachers pay close attention to students' psychological and emotional changes, to help them better to improve their physical education. In short, the university physical education teachers in the physical education should take full account of the actual situation of students, and then carry out a wide range of classroom teaching, and according to the classroom teaching content and teaching methods combine to ensure the scientific structure of classroom content, s efficiency.

Layered Teaching Promotes the Overall Development of Students. In the study of physical education, there are different differences between the individual students, and there are different interests among the students and the students 'knowledge and skill level are different. Therefore, the students' performance in the physical education class is different The In this situation, the implementation of physical education, to stimulate students' interest in sports at the same time, but also to meet the needs of different students, teachers should be based on the actual situation of students in the implementation of hierarchical teaching on the basis of playing a different student learning potential. In the process of physical education, teachers' hierarchical teaching is stratified by students, stratification of goals and stratification of teaching. For example, teachers can divide students into different groups based on their physical and physical performance, and then allow students to develop learning goals to achieve the desired goals of training so that students can improve their ability to work while improving brain mobility Enhance their emotional experience. In addition, teachers can also guide students to observe and understand, so that students in the observation of other students when the training to get better income and inspiration.

The Role of Modern Science and Technology in Education. In the traditional physical 
education is usually the way teachers lead students, and this approach is too mechanized, which will lead to students innovative thinking and personality thinking cannot be developed. At present, some modern science and technology for the development of education provides more convenience. For example, in the teaching of physical education using multimedia network technology to teach, to facilitate the teaching of teachers also help students better understand the knowledge and absorption [3]. Students learn in the form of multimedia teaching, get rid of the teacher-led teaching in the past, and teachers do not have to repeat the course to explain the content. In this modern technology, the sports teacher also has a new request, ask them not only to learn to master the basic knowledge of sports, and to learn to master the use of multimedia technology.

Experiential learning is a distinctive feature of modern independent innovation teaching model, in the process of strengthening the students at the same time to make the joy of success. Teachers in the physical education requires students to start training and development of appropriate goals, and students in order to achieve the goal, will practice in practice continue to overcome the difficulties and obstacles. After the practice, the students to their own evaluation, and students to start between the analysis and discussion, in such a differentiated treatment, can play a role in stimulating students' initiative and enthusiasm. For example, learning "jump high", teachers can implement the platform teaching methods, different levels of students set different levels of difficulty, so that students choose to autonomy. This kind of teaching method to a certain extent inspired students' self - confidence, so that each student experience success, so as to effectively improve the effect of physical education classroom.

\section{Conclusion}

In order to meet the requirements of modern college physical education teaching mode, we should vigorously promote the development of college students 'sports skills, cultivate and improve the level of college students' motor skills, establish the guiding ideology of "health first" through the research of university physical education teaching model, establish student-centered teaching concept; It is conducive to improving the college students' sports awareness, cultivate the interest of college students movement. In the teaching of physical education, teachers should be encouraged to establish new teaching ideas, combined with internal and external, through continuous practice and summary to explore suitable for Chinese sports teaching theory system to meet the needs of sports reform.

\section{References}

[1] Wang Man. Construction of Innovation System of College Physical Education Teaching Model Facing Sunshine Sports [J]. Journal of Southwest China Normal University (Natural Science Edition), 2014, 09: 185-188

[2] Liang Shuangshuang. Research on the Influence of Experiential Training Concept on the Reform of PE Teaching Mode in Colleges and Universities[J]. Journal of Nanjing University.2014

[3] Fu Jianqiang. Research on the teaching mode of public physical education in colleges and universities in shanghai from the perspective of "health promotion project"[D]. Shanghai Institute of Physical Education, 2013. 